\title{
Eine Katastrophe droht den Heimen
}

\author{
P. Günter
}

Von der breiten Öffentlichkeit noch unbemerkt, bahnt sich im Betreuungsund Behindertenbereich eine Katastrophe an. Auslöser ist die Neugestaltung des eidgenössischen Finanzausgleichs. Sogenannte Finanzspezialisten von Bund und Kantonen bescheren den Behindertenorganisationen und -institutionen einen drohenden Leistungsabbau. Im Kompetenzenschacher zwischen Bund und Kantonen drohen die Behinderten und ihre Heime bedenkenlos geopfert zu werden. Der Nationalrat wird als nächstes über den Neuen Finanzausgleich befinden. Für uns Ärztinnen und Ärzte ist es höchste Zeit, uns in die Diskussion einzuschalten - und gar notfalls ein Referendum gegen das neue Gesetz zu unterstützen.

Korrespondenz:

Dr. med. Paul Günter, Nationalrat Spital Interlaken

Institut für Anästhesie und

Intensivmedizin

CH-3800 Interlaken

E-Mail:

Paul.Guenter@spitalinterlaken.ch

\section{Die Kantonalisierung der Heime gefährdet eine gerechte Finanzierung}

Entscheidend für die Gefährdung der Heime ist im Vorschlag zum neuen Gesetz der Artikel 62 mit dem neuen Absatz 3. Er lautet: «Die Kantone sorgen für eine ausreichende Sonderschulung aller behinderten Kinder und Jugendlichen bis längstens zum vollendeten 20. Lebensjahr.»

Gleichzeitig soll der Artikel 112, Absatz 6 des bisherigen Gesetzes aufgehoben werden. Dieser lautet: «Der Bund fördert die Eingliederung Invalider und unterstützt Bestrebungen zugunsten Betagter, Hinterlassener und Invalider. Für diesen Zweck kann er Mittel aus der Alters-, Hinterlassenen- und Invalidenversicherung einsetzen.»

Was ist daran bedrohlich? Es ist die Tatsache, dass sich der Bund aus der Verantwortung für Behinderte, Hinterlassene und Betagte stehlen will. Die Kantone könnten dann frei entscheiden, was - gemäss ihrer zum Teil desolaten Finanzlage - «ausreichend» bedeutet. Es gibt also keine Zweckbindung mehr. Was geschieht, wenn die Bundes-Millionen, welche die Kantone für die Behinderten erhalten, grösstenteils in Steuersenkungen oder Strassenbauprogramme anstatt in Sonderschulen fliessen? Diese Schreckensvision ist nicht aus der Luft gegriffen. Der Konkurrenzkampf unter den Kantonen ist in den letzten Jahren immer härter geworden. Bisherige Sicherheit für Betagte, Hinter-
lassene und Behinderte beibehalten

Heute ist die Finanzlage für Heime nicht eben rosig, aber doch einigermassen befriedigend, weil flächendeckend gerecht aufgeteilt. Diese Verteilung musste hart erkämpft werden. Früher, als die Heime noch kantonal verwaltet wurden, musste z.B. von den Behindertenorganisationen um Beiträge für jedes Heim gestritten werden. In einigen, finanzschwachen Kantonen stand es schlimm um die Betreuung von Behinderten. In den 70er Jahren sorgte der Bund dafür, dass die Behinderten nicht mehr der Finanzwillkür der Kantone ausgeliefert waren. Heute werden die Heime in der ganzen Schweiz nach ähnlichen Kriterien geführt und finanziert. Diese Entwicklung war für alle Sonderschulen ein gewaltiger Fortschritt. Diese Praxis hat sich bewährt, sie funktioniert gut.

Aus der Sicht der Betroffenen gibt es nicht den geringsten Anlass, etwas zu ändern. Im Gegenteil: In der aktuellen Wirtschaftslage wird jede Änderung fast sicher zu einer deutlichen Verschlechterung führen.

\section{Die Volksabstimmung ist die Waffe der Betroffenen}

Der Ständerat hat das neue Gesetz bereits abgesegnet. Sollte der Nationalrat demnächst das gleiche tun, wird er das bisher Errungene leichtfertig aufs Spiel setzen. Was der Autor des Artikels aus der nationalrätlichen Kommission hört, lässt nichts Gutes erahnen. Sparer und Steuersenker haben das Sagen. Die Vertreter der Behinderten und der Betagten sind in der vorberatenden Kommission in der Minderheit.

Die Behindertenorganisationen verfügen aber über ein wirksames Instrument, Gegensteuer zu geben. Es ist das Nein in der Volksabstimmung. Im Volk dürfte die Sensibilität gegenüber einer falschen Kantonalisierung grösser sein, als in den Köpfen der Zahlenjongleure. 
Die Zeit drängt. Noch kann das Steuer herumgerissen werden. Ich sehe es als Pflicht von uns Ärztinnen und Ärzten an, hier für die Interessen der Behinderten, Hinterlassenen und Betagten einzustehen. Viele davon sind unsere Patienten. Aber auch sonst sollte uns der Schutz dieser Schwachen unserer Gesellschaft ein Anliegen sein.

\section{Die Chancen stehen gut}

Schon Anfang der 80er Jahre haben sogenannte Finanzfachleute unter dem Titel «Aufgabenteilung» versucht, eine Kantonalisierung auf dem
Buckel der Betroffenen durchzusetzen. Damals ist es engagierten Gruppen gelungen, das Projekt bereits in der Vernehmlassungsphase zu stoppen.

Diesmal haben wir zu lange auf die Einsicht massgebender Politiker vertraut. Es ist Fünf vor Zwölf geworden. Eine gute Möglichkeit, politisch Druck zu erzeugen ist die Vorbereitung einer Nein-Kampagne für den Fall, dass der neue Finanzausgleich nicht auf die Kantonalisierung der Heime verzichtet. Ich hoffe, dass viele Ärztinnen und Ärzte dabei helfen. Geben wir den Behinderten, Betagten und Hinterlassenen die Gewissheit, dass wir für ihr Wohl einstehen und sie nicht der Willkür der Kantone ausliefern wollen. 